\title{
Adrenal insufficiency, be aware of drug interactions!
}

\author{
Elke Thijs ${ }^{1}$, Katrien Wierckx² ${ }^{2}$ Stefaan Vandecasteele ${ }^{3}$ and Annick Van den Bruel ${ }^{4}$ \\ ${ }^{1}$ Internal Medicine, University Hospital, Ghent, Belgium, ${ }^{2}$ Endocrinology, OLV Hospital, Aalst, Belgium, ${ }^{3}$ Nephrology
}

- Infectious Diseases, A.Z.-Sint Jan, Bruges, Belgium, and ${ }^{4}$ Endocrinology, A.Z.-Sint Jan, Bruges, Belgium

Correspondence should be addressed to A Van den Bruel

Email

Annick.VandenBruel@ azsintjan.be

\section{Summary}

A 42-year-old man with complaints of muscle soreness and an increased pigmentation of the skin was referred because of a suspicion of adrenal insufficiency. His adrenocorticotropic hormone and cortisol levels indicated a primary adrenal insufficiency (PAl) and treatment with hydrocortisone and fludrocortisone was initiated. An etiological workup, including an assessment for anti-adrenal antibodies, very long-chain fatty acids, $17-\mathrm{OH}$ progesterone levels and catecholamine secretion, showed no abnormalities. 18Fluorodeoxyglucose positron emission tomography/CT showed bilateral enlargement of the adrenal glands and bilateral presence of an adrenal nodule, with 18fluorodeoxyglucose accumulation. A positive tuberculin test and positive family history of tuberculosis were found, and tuberculostatic drugs were initiated. During the treatment with the tuberculostatic drugs the patient again developed complaints of adrenal insufficiency, due to insufficient dosage of hydrocortisone because of increased metabolism of hydrocortisone.

\section{Learning points:}

- Shrinkage of the adrenal nodules following tuberculostatic treatment supports adrenal tuberculosis being the common aetiology.

- The tuberculostatic drug rifampicin is a CYP3A4 inducer, increasing the metabolism of hydrocortisone. Increase the hydrocortisone dosage upon initiation of rifampicin in case of (adrenal) tuberculosis.

- A notification on the Addison's emergency pass could be considered to heighten physician's and patients awareness of hydrocortisone drug interactions.

\section{Background}

Primary adrenal insufficiency (PAI) is a rare, but potentially life-threatening disease, with a reported prevalence of 100-140 cases per million and an incidence of 4:1 000 000 per year in Western societies $(1,2)$.

In Western Europe the most common cause of PAI is autoimmunity, accounting for $80-90 \%$ of all cases, which can be isolated (40\%) or part of an autoimmune polyendocrinopathy syndrome (60\%). Other possible causes include infection (e.g. tuberculosis (TB)), adrenal haemorrhage, genetic disorders (e.g. congenital adrenal hyperplasia, adrenoleukodystrophy), infiltrative disease (e.g. amyloidosis, haemochromatosis, lymphoma) or medication induced (e.g. ketoconazole) $(1,3)$. In developing countries or immigrant populations, the differential diagnosis should always include tuberculous adrenalitis (3).

The adrenal glands are a common site of extrapulmonary tuberculosis. Mycobacterium tuberculosis spreads to the adrenal glands (haematogenous or lymphogenous spread) and adrenal involvement was found in about $6 \%$ of patients with active tuberculosis (4). The adrenal glands are often (70\%) bilaterally involved. Caseous necrosis causes destruction of the adrenal glands and adrenal insufficiency occurs when at least $90 \%$ of the adrenal gland is destroyed.

Adrenal biopsy is usually not necessary for PAI with bilateral adrenal enlargement in a patient with proven

(c) 2019 The authors $\begin{array}{r}\text { https://edm.bioscientifica.com/ } \\ \text { Published by Bioscientifica Ltd }\end{array}$


extra-adrenal tuberculosis. However, about $12 \%$ of patients with adrenal tuberculosis have no evidence of active extra-adrenal tuberculosis (5). Adrenal biopsy is generally necessary in these patients to confirm diagnosis.

\section{Case presentation}

A 42-year-old man with complaints of muscle soreness and an increased pigmentation of the skin was referred to the Department of Endocrinology because of a suspicion of adrenal insufficiency. There were no other complaints at the time of referral. The patient was known to have suffered from arterial hypertension, which was well controlled despite discontinuation of all antihypertensive drugs. Beside arterial hypertension, the patient also suffered from gastro-oesophageal reflux for which he was being treated with a proton pump inhibitor (Esomeprazole $20 \mathrm{mg}$ daily). His family history showed no peculiarities. There had not been any visits to the tropics and the patient denied any drug abuse.

Physical examination revealed a normal blood pressure with an increased pulse rate and a striking hyperpigmentation of the skin and mucosal tissues (Fig. 1). His weight was $89 \mathrm{~kg}$. Laboratory findings showed a low morning cortisol, low DHEAS, high renin and high ACTH concentration. A short corticotrophin test could not provoke a marked increase in serum cortisol concentration (Table 1). The patient was diagnosed with primary adrenal insufficiency (PAI) and treatment with hydrocortisone $(15 \mathrm{mg}+5 \mathrm{mg} /$ day $)$ and fludrocortisone $(50 \mu \mathrm{g} /$ day $)$ was initiated.

\section{Investigation}

An etiological workup was performed, including an assessment for anti-adrenal antibodies and catecholamine secretion, which was negative. 17-OH progesterone levels and very long-chain fatty acids were normal. A computed tomography of the adrenals was performed, showing bilateral enlargement of the adrenals and bilateral presence of an adrenal nodule (right: nodule with maximum diameter $44 \mathrm{~mm}$, Hounsfield units (HU) 40; left: maximum diameter $14 \mathrm{~mm}, \mathrm{HU}$ : 37). (Fig. 2, panel A). Further examination with a whole-body fluorine-18 fluorodeoxyglucose positron emission tomography-CT (FDG PET-CT) showed an increased FDG uptake in both adrenals (more pronounced on the right side), as well as an increased uptake in some axillary lymph nodes. A tuberculin skin test showed to be positive and may reflect either co-existence of $\mathrm{TB}$ carriage or $\mathrm{TB}$ of the
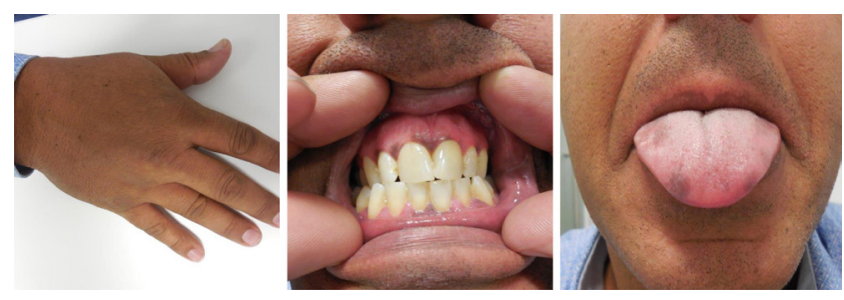

Figure 1

Hyperpigmentation of skin and mucosae.

adrenal glands. Due to absence of extra-adrenal TB, a further work-up with ultrasonic-guided puncture of an adrenal gland was planned. Unfortunately the procedure appeared to be technically impossible because of the high risk of a hepatic bleeding. On retrospect, a more elaborate family history revealed the patient's mother, a nurse, had been treated for work-related TB exposure 10 years before.

\section{Treatment}

An empirical treatment with a combination of tuberculostatic drugs was initiated (combination of rifampicine $600 \mathrm{mg} /$ day, nicotibine $300 \mathrm{mg} /$ day, pyridoxine $250 \mathrm{mg} /$ week, tebrazid $500 \mathrm{mg} 4 /$ day, myambutol $400 \mathrm{mg}$ 4/day) and continued for 9 months (except for tebrazid and myambutol: 2 months). The effect of the treatment was assessed after 6 months with CT imaging of the adrenals showing a significant decrease in volume of the adrenals (Fig. 2, panel B).

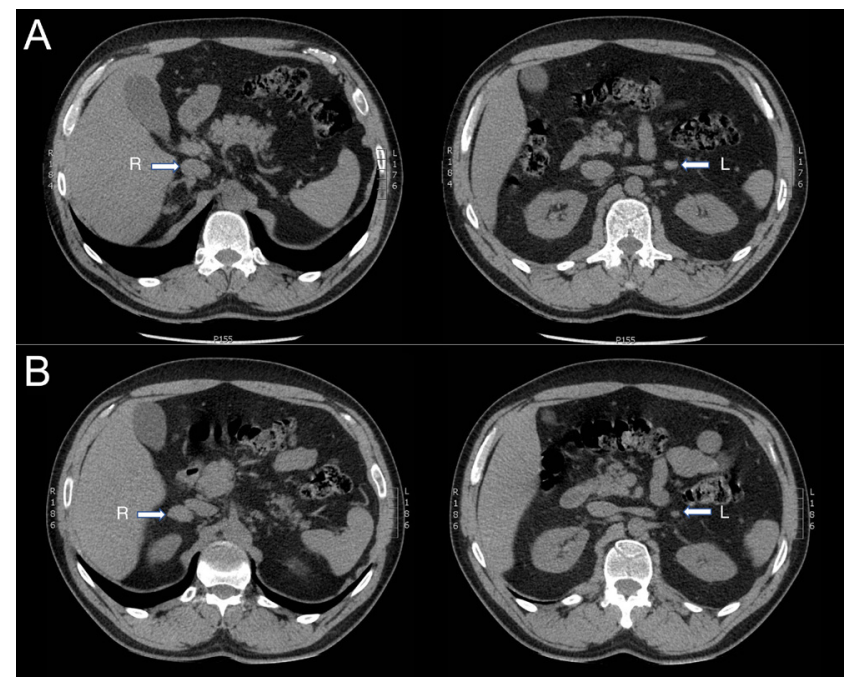

\section{Figure 2}

CT scan of the adrenals. Axial slices at diagnosis (panel A): right adrenal measuring $30 \times 17 \mathrm{~mm}$, left adrenal measuring $13 \times 8 \mathrm{~mm}$. A control scan 10 months after initiation of tuberculostatic drugs showed a shrinkage of the nodular adrenals (right adrenal: $26 \times 14 \mathrm{~mm}$, left adrenal: $7 \times 5 \mathrm{~mm}$, panel B). 
Table 1 Laboratory findings.

\begin{tabular}{|c|c|c|}
\hline Parameters & Values & Reference range \\
\hline Morning cortisol, $\mu \mathrm{g} / \mathrm{dL}$ & 2 & $6.2-18$ \\
\hline $\begin{array}{l}\text { Cortisol 0' after corticotrophin, } \\
\mu \mathrm{g} / \mathrm{dL}\end{array}$ & 1.6 & \\
\hline $\begin{array}{l}\text { Cortisol 30' after corticotrophin, } \\
\mu \mathrm{g} / \mathrm{dL}\end{array}$ & 1.5 & \\
\hline $\begin{array}{l}\text { Cortisol 60' after corticotrophin, } \\
\mu \mathrm{g} / \mathrm{dL}\end{array}$ & 1.5 & \\
\hline DHEAS, $\mu \mathrm{g}$ & 67 & $88.9-427$ \\
\hline Renin, $\mu \mathrm{IU} / \mathrm{mL}$ & 15187 & $2.8-39.9$ \\
\hline ACTH, $\mu \mathrm{g} / \mathrm{L}$ & $>1250$ & \\
\hline
\end{tabular}

\section{Outcome and follow-up}

During the treatment with the tuberculostatic drugs the patient again developed complaints of muscle soreness and hypotension, being symptoms of an insufficient dosage of hydrocortisone. This higher need of hydrocortisone could be explained by Rifampicine induced induction of CYP3A4, which is the key enzyme in metabolizing hydrocortisone. By increasing the dose of hydrocortisone to $15 \mathrm{mg}$ tid (instead of $15 \mathrm{mg}$ before the introduction of rifampicin), an Addison crisis was averted. Later on, the dose was slightly reduced to 20-10-10 mg daily. The dose of fludrocortisone effective to eliminate hyponatremia was fludrocortisone $75-50 \mu$ g daily (instead of $75 \mu$ g before the use of rifampicin).

\section{Discussion}

PAI is a rare condition with a reported prevalence of about 100-140 cases per million in Western societies $(2,4,6)$. The most common cause of PAI is auto-immunity (up to $90 \%$ in Western countries) (2). In developed countries, adrenal $\mathrm{TB}$ is a relatively infrequent cause of PAI, whereas in developing countries it remains the major cause. However, recent human migration waves have contributed to increased rates of $\mathrm{TB}$ in Western societies. In this particular patient, the differential diagnosis included an isolated adrenal $\mathrm{TB}$ and other causes of bilateral adrenal enlargement such as primary or secondary neoplastic disease and infectious diseases (other than TB) (7). In ideal circumstances, after exclusion of bilateral pheochromocytoma, a confirmation of the diagnosis is obtained by an adrenal puncture to provide microbiological and histopathological examination.

When initiating a treatment for adrenal $\mathrm{TB}$, it should be taken into account that rifampicine is a strong CYP3A4 inducer. CYP 3A4 is the key drug-metabolizing enzyme affecting hydrocortisone clearance. Concomitant treatment with antituberculotic drugs can cause a significant reduction in hydrocortisone efficacy. There are no specific guidelines concerning dose adjustments of hydrocortisone therapy in patients receiving CYP 3A4 inducers. Some recommend to double or even triple the dose of adrenal steroids in patients with PAI (8). Others tend to use plasma cortisol levels $2 \mathrm{~h}$ after administration of the morning dose of hydrocortisone (9). A pharmacokinetic study of Rousseau et al. showed a strong correlation between those levels and the daytime cortisol profile on a thrice daily regimen (9). Nevertheless, clinical monitoring of glucocorticoid replacement therapy in these cases is very important to avoid an Addison crisis (1). Therefore, the addition of hydrocortisone drug interactions onto the Addison's emergency card could be considered.

PAI due to adrenal TB is not expected to recover following treatment with tuberculostatic drugs and therefore lifelong treatment is needed (10).

\section{Conclusion}

In case primary adrenal insufficiency and bilateral adrenal masses are diagnosed together, tuberculosis is part of the differential diagnosis. If so, tuberculostatic treatment should be initiated with great caution since rifampicine is a strong CYP3A4 inducer requiring a higher hydrocortisone replacement dosage. Bilateral adrenal masses may shrink during treatment. The Clinical Practice Guideline on primary adrenal insufficiency mentions the need of an increased dosage of hydrocortisone in case of administration of CYP3A4 inducing co-medications. However, a specific notification on the Addison's emergency pass could be considered an aid to reinforce this measure in clinical practice.

Declaration of interest

The authors declare that there is no conflict of interest that could be perceived as prejudicing the impartiality of the research reported.

\section{Funding}

This research did not receive any specific grant from any funding agency in the public, commercial or not-for-profit sector.

\section{Patient consent}

Informed consent for the publication of clinical data and photographs has been obtained from the patient.

\section{Author contribution statement}

All authors were involved in patient care and contributed to the manuscript. 


\section{References}

1 Husebye ES, Allolio B, Arlt W, Badenhoop K, Bensing S, Betterle C, Falorni A, Gan EH, Hulting AL, Kasperlik-Zaluska A, et al. Consensus statement on the diagnosis, treatment and follow-up of patients with primary adrenal insufficiency. Journal of Internal Medicine 2014275 104-115. (https://doi.org/10.1111/joim.12162)

2 Bornstein SR, Allolio B, Arlt W, Barthel A, Don-wauchope A, Hammer GD, Husebye ES, Merke DP, Murad MH, Stratakis CA, et al. Diagnosis and treatment of primary adrenal insufficiency : an Endocrine Society clinical practice guideline. Journal of Clinical Endocrinology and Metabolism 2016101 364-389. (https://doi. org/10.1210/jc.2015-1710)

3 Charmandari E, Nicolaides NC \& Chrousos GP. Adrenal insufficiency. Lancet 2014383 2152-2167. (https://doi.org/10.1016/S01406736(13)61684-0)

4 Lam KY \& Lo CY. A critical examination of adrenal tuberculosis and a 28-year autopsy experience of active tuberculosis. Clinical Endocrinology 200154 633-639. (https://doi.org/10.1046/j.13652265.2001.01266.x)

5 Kelestimur F, Unlu Y, Ozesmi M \& Tolu I. A hormonal and radiological evaluation of adrenal gland in patients with acute or chronic pulmonary tuberculosis. Clinical Endocrinology $1994 \mathbf{4 1}$ 53-56. (https://doi.org/10.1111/j.1365-2265.1994.tb03784.x)

6 Laureti S, Vecchi L, Santeusanio F \& Falorni A. Letters to the editor: is the prevalence of addison's disease underestimated? Journal of Clinical Endocrinology and Metabolism 199984 1758-1759.

7 Oelkers W. Adrenal insufficiency. New England Journal of Medicine 1996335 1206-1212. (https://doi.org/10.1056/ NEJM199610173351607)

8 Kyriazopoulou V, Parparousi O \& Vagenakis AG. Rifampicin-induced adrenal crisis in addisonian patients receiving corticosteroid replacement therapy. Journal of Clinical Endocrinology and Metabolism 198459 1204-1206. (https://doi.org/10.1210/jcem-59-6-1204)

9 Kusuki K, Watanabe S \& Mizuno Y. Tuberculous Addison's disease with increased hydrocortisone requirements due to administration of rifampicin. BMJ Case Reports 201912 228-293. (https://doi. org/10.1136/bcr-2018-228293)

10 Rousseau E, Joubert M, Trzepla G, Parienti JJ, Freret T, Vanthygem MC, Desailloud R, Lefebvre H, Coquerel A, Reznik Y, et al. Usefulness of time-point serum cortisol and ACTH measurements for the adjustment of glucocorticoid replacement in adrenal insufficiency. PLOS ONE 201510 e0135975. (https://doi. org/10.1371/journal.pone.0135975)

Received in final form 11 August 2019

Accepted 6 September 2019 